\title{
Resistivity structure across Itoigawa-Shizuoka tectonic line and its implications for concentrated deformation
}

\author{
Yasuo Ogawa ${ }^{1}$, Shinichi Takakura ${ }^{2}$, and Yoshimori Honkura ${ }^{3}$ \\ ${ }^{1}$ Volcanic Fluid Research Center, Tokyo Institute of Technology, Tokyo 152-8551, Japan \\ ${ }^{2}$ Institute of Geo-Resources and Environment, AIST, Tsukuba, Ibaraki 305-8567, Japan \\ ${ }^{3}$ Department of Earth and Planetary Sciences, Tokyo Institute of Technology, Tokyo 152-8551, Japan
}

(Received January 20, 2002; Revised September 9, 2002; Accepted October 11, 2002)

\begin{abstract}
We investigated the deep crustal resistivity structure across Itoigawa-Shizuoka Tectonic Line (ISTL), one of the most dangerous active intraplate faults in Japan, by use of wide-band magnetotelluric (MT) method. The 28 MT stations were aligned perpendicular to the ISTL. A two-dimensional model was created in transverse magnetic (TM) mode where electric currents flow in $\mathrm{N} 60^{\circ} \mathrm{W}-\mathrm{N} 120^{\circ} \mathrm{E}$ directions. The model showed good correlations with the surface geology. In particular, we found a thick $(\sim 6 \mathrm{~km})$ surface conductor to the east of ISTL which corresponds to the heavily folded sedimentary layer. The Japan Alps to the west of the ISTL is characterized by the resistive upper crust, where the pre-Tertiary rocks crop out. The Japan Alps is underlain by a conductor below 15-20 km depth, which is consistent with the low seismic velocity anomaly. We also found a localized shallow conductor corresponding to the Mt. Tateyama volcano. The most important feature is the conductor in the mid-crust directly under the area of active folding to the east of the ISTL. This may imply a localized zone of fluids because of the enhanced porosity in a shear zone. The recent seismicity clusters in the resistive crust underlain by the conductor, and this suggests the fluid involvement in earthquake generation processes.
\end{abstract}

\section{Introduction}

The magnetotelluric (MT) method can produce electrical resistivity images of the deep crust and upper mantle by measuring natural electromagnetic signals at the earth surface in a wide frequency band at many site locations (e.g., Jones, 1992). As the resistivity of rocks is sensitive to distributions of fluids, MT can be a powerful tool in investigating the fluid involvement in the earthquake generation processes. Unsworth et al. (1999) report the effectiveness of MT in delineating the fracture zones as conductive features in the San Andreas Fault zone in California. MT can also characterize the deeper structure of the seismogenic zones in terms of electric resistivity (Lemonnier et al., 1999; Honkura et al., 2000; Ogawa et al., 2001; Mitsuhata et al., 2001).

The objective of this study is to image the deep structure across Itoigawa-Shizuoka tectonic line (ISTL, see Fig. 1), which is believed as the Eurasian/North American plate boundary on land (Kobayashi, 1983; Nakamura, 1983). In particular, the northern segment of the tectonic line is regarded as one of the most dangerous active faults in Japan. This study is a part of the multidisciplinary project to study the deep slip process on faults that might precede large intraplate earthquakes.

\section{Previous Magnetotelluric Studies in Seismo- genic Regions}

Recent MT studies in Japan over seismically active re-

Copy right(c) The Society of Geomagnetism and Earth, Planetary and Space Sciences (SGEPSS); The Seismological Society of Japan; The Volcanological Society of Japan; The Geodetic Society of Japan; The Japanese Society for Planetary Sciences. gions have detected several conductors under the seismogenic zones. The high seismicity clusters in the resistive region near the resistivity boundary or in the resistive region underlain by conductor (Ogawa et al., 2001; Mitsuhata et al., 2001).

Ogawa et al. (2001) collected MT data on a $90 \mathrm{~km}$ long profile with 34 stations in the back arc of the Northeast Japan (profile 1 in Fig. 1). The present day high seismicity is regarded as aftershocks of two historically known large intraplate earthquakes, Senboku earthquake (M7.1 in 1914) and Rikuu earthquake (M7.2 in 1896). The MT data showed strong two-dimensionality and anisotropic responses at the periods around $100 \mathrm{~s}$. The resistivity model required three mid-crustal conductive blocks that were not connected in a horizontal direction. The correlations of the conductors to the seismic scatterers and to the low velocity anomalies suggest that the conductors represent fluids. Clusters of seismicity near the edges of conductors (Umino et al., 2000) suggest that the intraplate seismicity might result from the migration of the fluids to less permeable regions of the crust (Ague et al., 1998).

Mitsuhata et al. (2001) presented the results of detailed MT profiling around a seismically active region in the forearc of Northeastern Japan (profile 2 in Fig. 1). The current seismicity is interpreted as aftershock of Northern Miyagi Earthquake (M6.5) in 1962. A two-dimensional inversion revealed the existence of a deep conductive zone and overlying resistive zone in the upper crust. They found that the micro-earthquakes occur just above the deep conductor and in the resistive zone, and that several S-wave reflectors are just above the deep conductor. Since the S-wave reflectors 
suggest the existence of fluid beneath them, the deep conductor was interpreted as a fluid-filled zone. They suggested that the seepage of the fluid from the conductive fluid-filled zone to the resistive granitoid pluton might trigger the earthquakes swam.

These previous studies found a consistent relationship between electromagnetic images and regions of high seismicity, which are aftershock regions of historically known large intraplate earthquakes (Fig. 2(a)). Namely, the high seismicity corresponds to the resistive area underlain by the conductor, or the one near the conductor. This suggests the fluid involvement in generating the aftershocks.

In this study, we are most interested in the earthquake potential of the region where intraplate earthquakes may happen in the near future (Iio and Kobayashi, 2002). We evaluate two such test sites in Japan. One is the northern segment of ISTL in Nagano prefecture; the other is Nagamachi-Rifu line in Miyagi prefecture (e.g., Sato et al., 2002). The hypothesis that we plan to test is that the quasi-stationary slip in the lower crust precedes the incidence of a large intraplate earthquake (Fig. 2(b)). The slip area must be localized as expected by geological observations at the outcrop of the fossil shear zones (e.g., Fujimoto et al., 2002). We test if the fluid is involved in the localization of the deep slip process. In this paper we show MT results from one of the test areas, Itoigawa-Shizuoka tectonic line.

\section{Geological Background}

ISTL is a geological boundary between the Pre-Tertiary unit to the west and the Neogene units to the east. The PreTertiary basement deepens to the east. The northern segment of the ISTL is an active thrust fault. The recurrence time of the earthquake faulting is estimated as less than 1000 years from the trenching of the active segment in Matsumoto (Fig. 3) (Okumura et al., 1994).

In the Miocene, at the time of the Japan Sea opening, ISTL was created as a normal fault in an extensional tectonics. The Minochi belt (Fig. 3) is made up of thick (several kilometers)

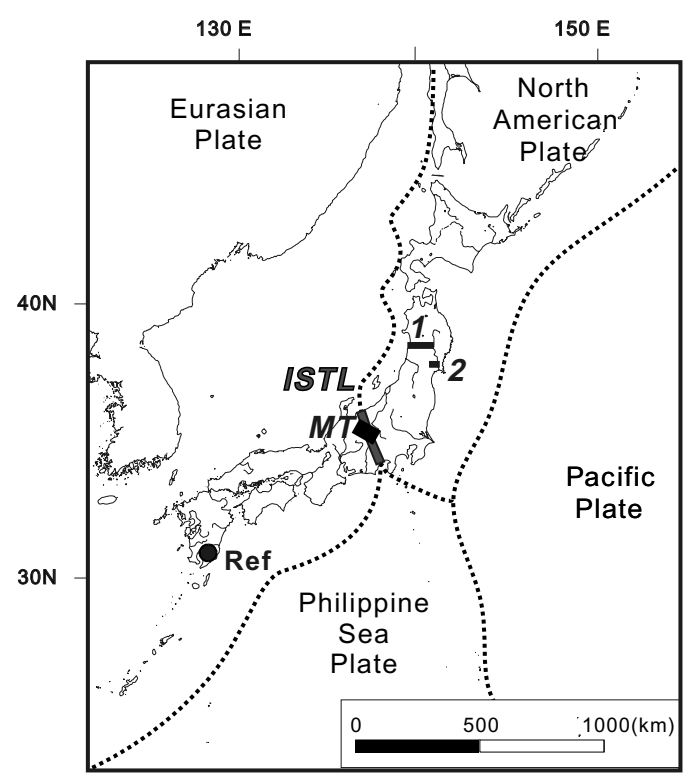

Fig. 1. Location of Itoigawa-Shizuoka Tectonic Line (ISTL) as part of the plate boundary between the North American plate and the Eurasian plate. Ref is the remote reference site for MT. Two profiles identified as 1 and 2 denote the locations of the previous MT survey over intraplate earthquake regions (Ogawa et al., 2001; Mitsuhata et al., 2001), respectively.
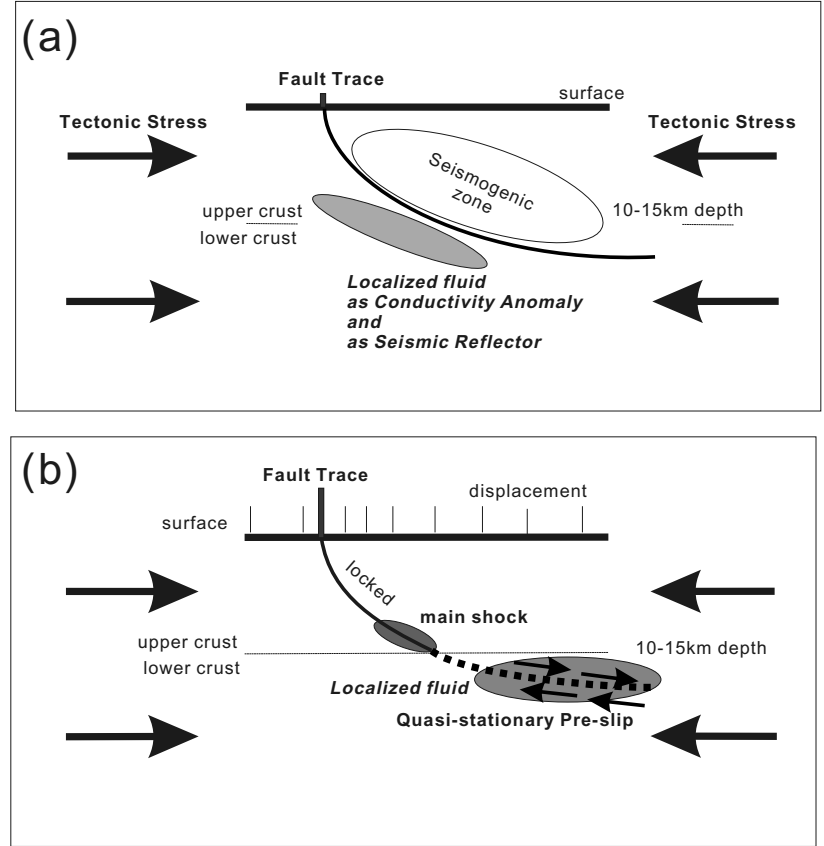

Fig. 2. Schematic resistivity models for (a) after and (b) before the large intraplate earthquakes.

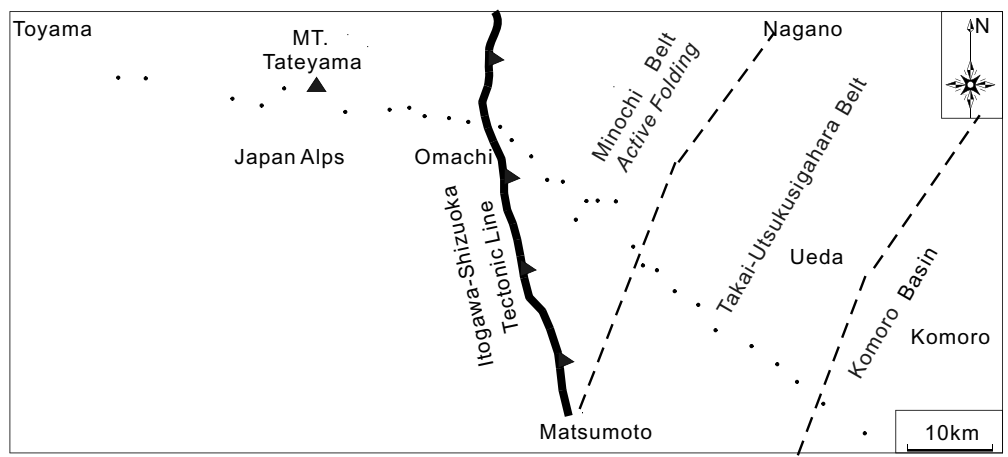

Fig. 3. MT site locations and major geological units. 
layers of marine sediments and volcanics, which deposited under the Miocene extension tectonics. Later to the present, ISTL was reactivated in a compressional tectonics as a reactivated fault (Sato and Ikeda, 1999). The tectonic compression also folded the Minochi belt to the east of the ISTL. These geological observations are consistent with the geodic results that show large shortenings in the Minochi belt of 30 ppm per 100 years (Sagiya et al., 2002). Thus this area is

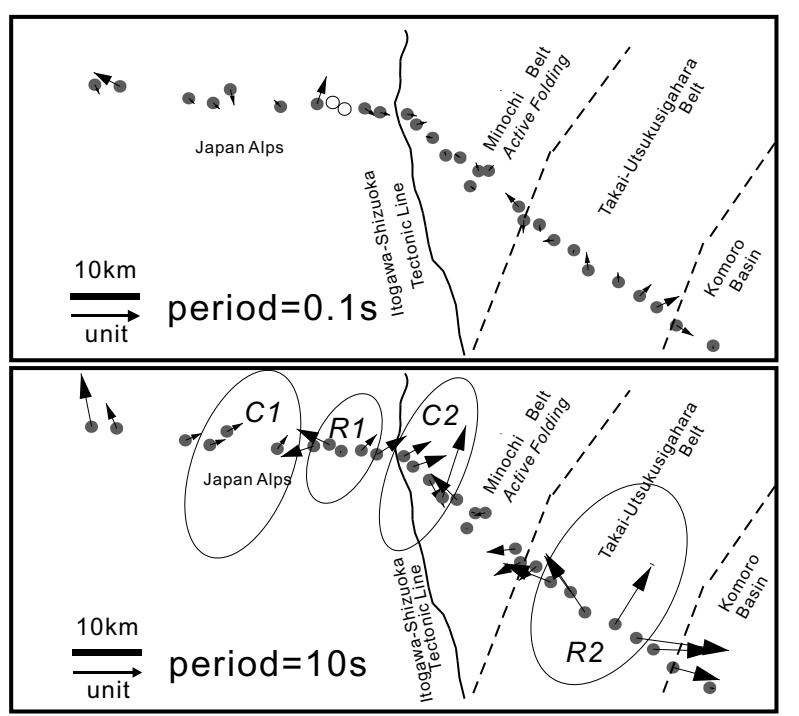

Fig. 4. Real parts of the induction vectors at the period of (a) $0.1 \mathrm{~s}$ and (b) $10 \mathrm{~s}$. The vectors point to conductors and the unit length corresponds to $10 \mathrm{~km}$. At $10 \mathrm{~s}$, they point toward the conductive anomalies $(\mathrm{C} 1, \mathrm{C} 2)$ and away from the resistive anomalies (R1, R2). thought suitable to test the hypothesis of deep slip in active faults.

The Japan Alps (the Hida mountain range) is located west of ISTL. According to Ikeda (1996), the basic topography was created in the Miocene in the extensional tectonics. The continuation of the regional tensile stress created Quaternary monogenic volcanoes such as Mt. Tateyama, which is characterized by the youngest granitic intrusion on Earth (Harayama, 1992). In order to investigate the deep structure of ISTL, we must also analyze the surrounding regional structure around the target area (Ogawa, 2002).

\section{Magnetotelluric Observations}

The $100 \mathrm{~km}$ long MT profile of 28 stations runs across the ISTL (Fig. 3). From the west to the east, it crosses the Japan Alps (Hida Mountains), the Minochi belt (area of active folding), the Takai-Utsukusigahara belt (area of elevated basement), and the Komoro collapse basin.

The data were collected in September 2000 using 6 wideband MT instruments (Phoenix MTU5 system). The period range covers from $3 \times 10^{-3} \mathrm{~s}$ to $2,000 \mathrm{~s}$. Since the DC electric railways severely affect the measurements, the time series analysis was focused on the nocturnal data when there were fewer trains. We also had simultaneous remote reference measurement site operating on Kyushu island (Ref in Fig. 1), which is approximately $900 \mathrm{~km}$ away from the study area. Using remote reference technique (Gamble et al., 1979), we could reduce the unwanted cultural noise mainly from leakage currents of DC railways in the study area.

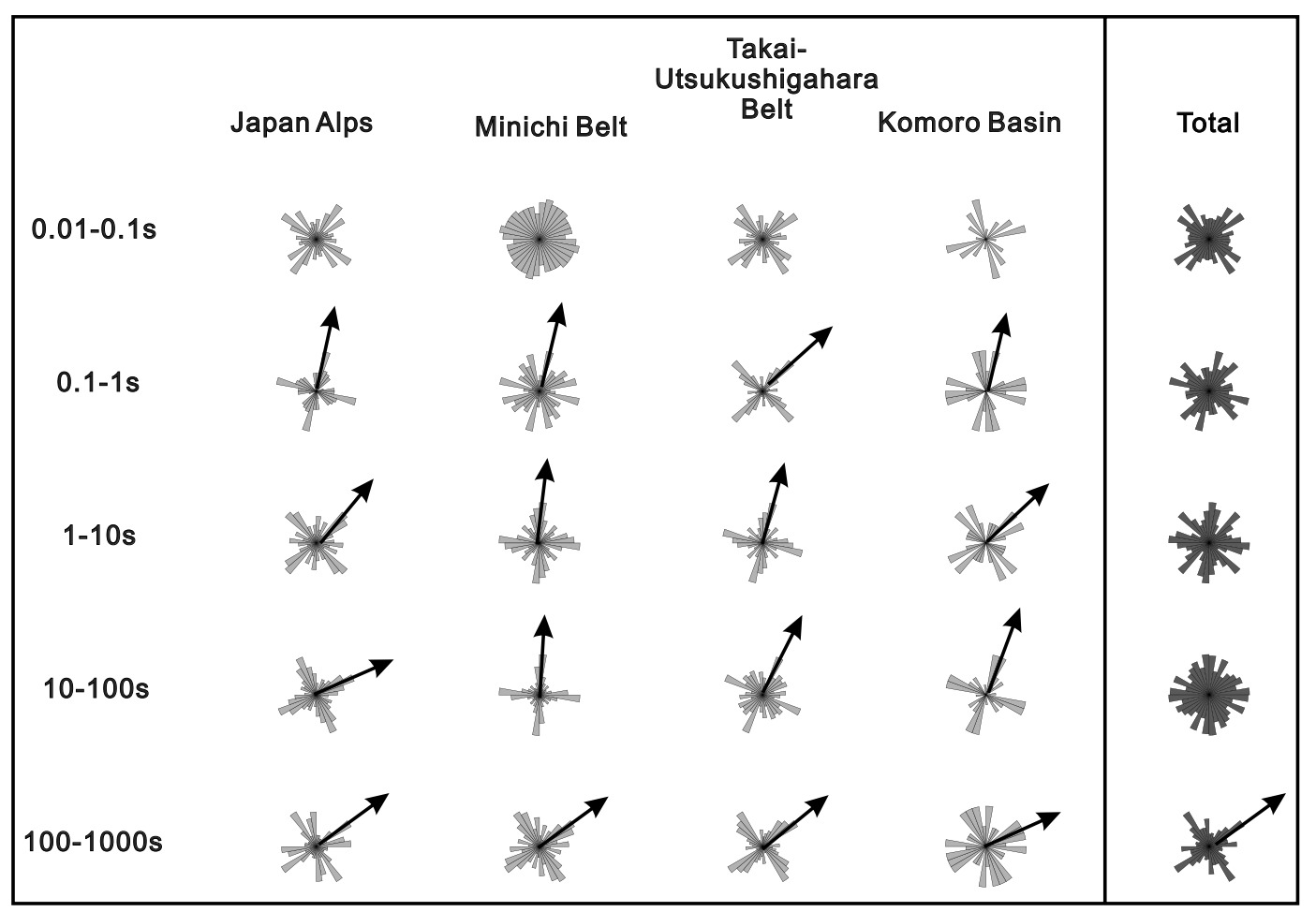

Fig. 5. Strike estimates from the Groom-Bailey tensor decompositions, where distortion parameters were set site-dependent and period-dependent. This shows the period and spatial dependence of the directional properties of the resistivity structure. Note that the $\pi / 2$ ambiguities are also included in each diagram. 
(a)

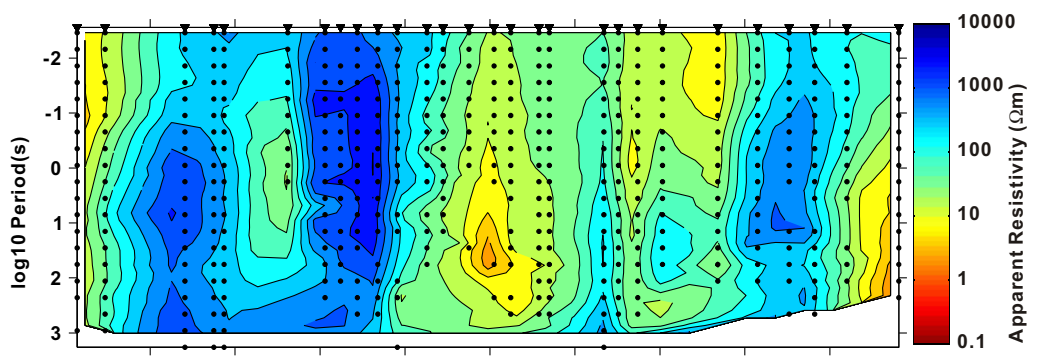

(b)

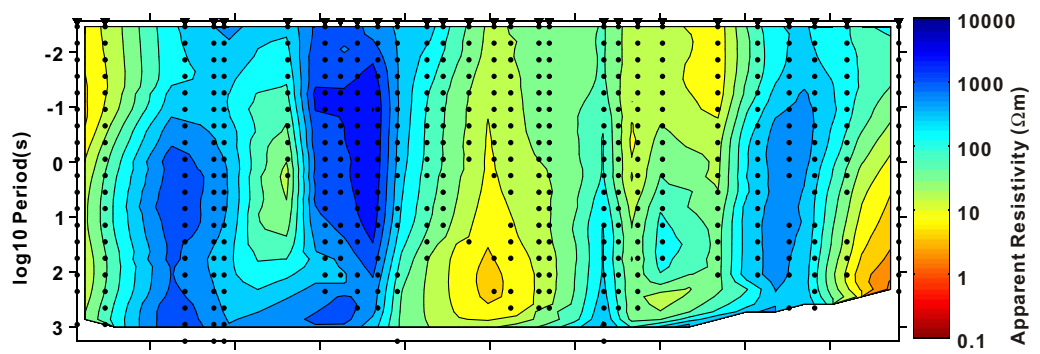

(c)

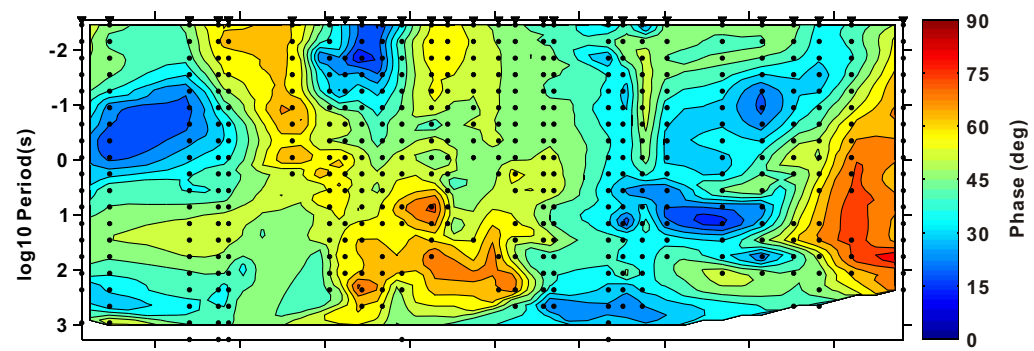

(d)

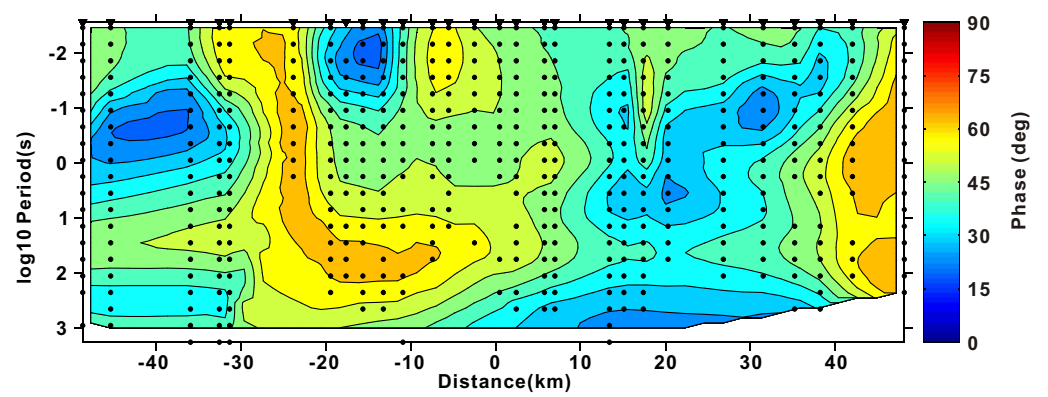

Fig. 6. Pseudo-sections for the observed and calculated apparent resistivity and phase for the TM mode (electric current in N60 ${ }^{\circ} \mathrm{W}-\mathrm{N} 120^{\circ} \mathrm{E}$ direction); (a) observed apparent resistivity, (b) calculated apparent resistivity, (c) observed phase, and (d) calculated phase, respectively.

\section{Checking Dimensionality}

Prior to the two-dimensional analyses, we diagnosed the dimensionality of the data, by the induction vectors and the impedance strike distributions.

\subsection{Induction vectors}

Induction vectors show the regional resistivity contrast inferred from magnetic fields. Figure 4 show the real parts of the induction vectors at the periods of (a) $0.1 \mathrm{~s}$ and (b) $10 \mathrm{~s}$. In the short period (Fig. 4(a)) the vectors are small and there is no regional distribution. However, at the period of $10 \mathrm{~s}$ (Fig. 4(b)), we have concentrations of induction vectors to $\mathrm{C} 1$ in the Japan Alps and C2 below the western part of the Minochi belt (active folding zone). Resistive anomalies can also be identified as the vectors point outward at R1 and R2. These anomalies are consistent with the mid-crustal structure as shown later.

\subsection{Impedance strike estimates}

We estimated strike directions from individual impedance data, by tensor decompositions (Groom and Bailey, 1989).
Figure 5 shows the distribution of strike estimates for perioddependent, site-dependent decompositions. We can see the consistency within each geologic unit and within each decade band of periods. Only in the longest period band (100-1000 s), we have consistent direction over the whole profile. In the shorter periods, the strike estimates mostly fell between $\mathrm{N} 0^{\circ} \mathrm{E}$ and $\mathrm{N} 45^{\circ} \mathrm{E}$. As a preliminary modeling, we took $\mathrm{N} 30^{\circ} \mathrm{E}$ as a regional strike direction, which follows the major geological boundaries east of ISTL.

\section{Two-Dimensional Magnetotelluric Modeling}

We assumed that the regional strike direction as $\mathrm{N} 30^{\circ} \mathrm{E}$. As seen from Fig. 3, the assumed strike is consistent with the surface geological divisions to the east of the ISTL. However, obviously the ISTL is oblique to this direction.

The southward extension of the eastern geologic units, especially Minochi belt, is chopped by the ISTL. As the Minochi belt has thick conductive surface layers (as shown later), the use of just the TM mode here may be more reliable 

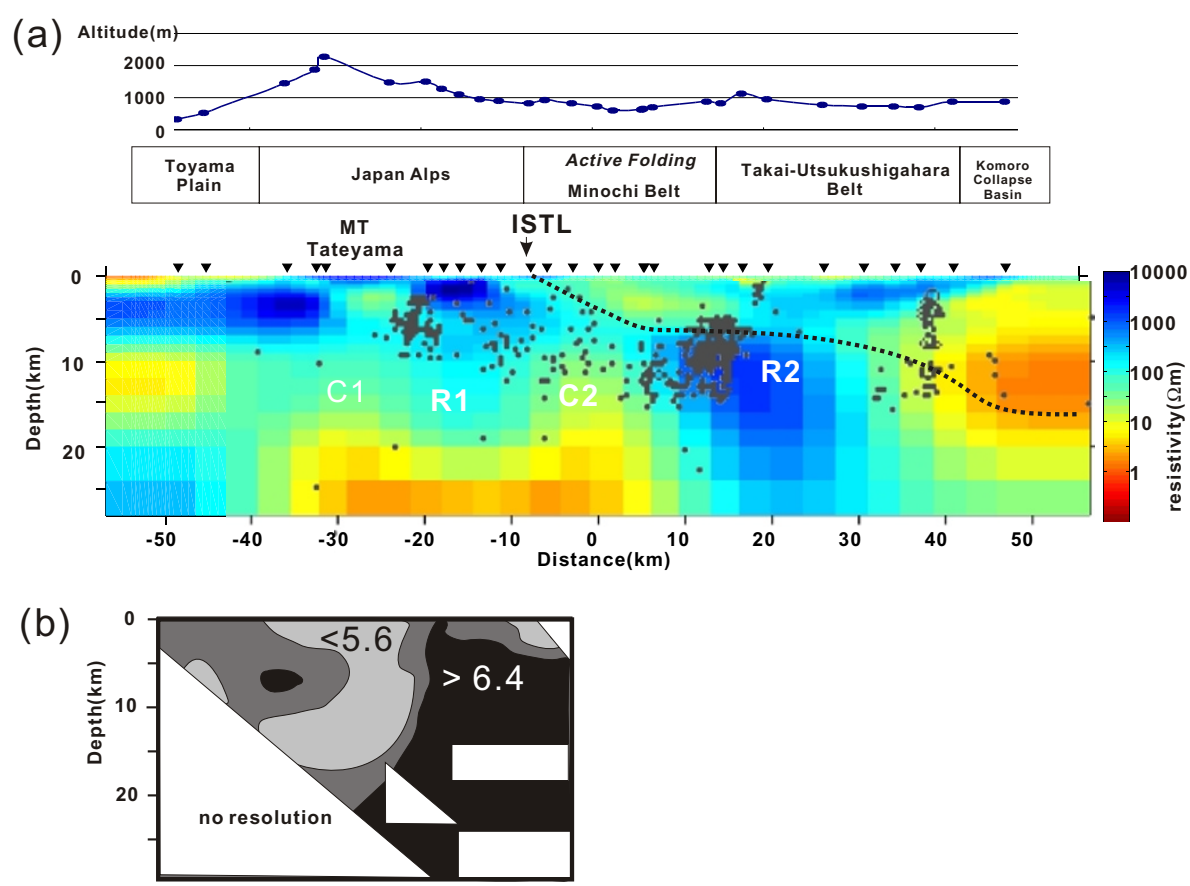

Fig. 7. (a) A two-dimensional resistivity model and the seismicity along the profile. The resistivity model used TM mode only where electric field is across the assumed strike direction of $\mathrm{N} 30^{\circ}$ E. Altitude of the sites and geological belts are also shown. (b) Seismic tomography result over the Japan Alps, simplified from Matsubara et al. (2000).

than using both TE and TM modes (Wannamaker et al., 1984; Ogawa, 2002).

We used a uniform earth of $100 \Omega \mathrm{m}$ as the initial model. The inversion had a constraint that the resistivity structure should be spatially smooth (Ogawa and Uchida, 1996). Thus the obtained model is the smoothest model that can fit the data. Figure 7 shows the resistivity model. The rms converged to 1.02 with an assumed error floor of $10 \%$ in apparent resistivity and the equivalent in phase.

Figure 6 shows the comparisons between observed and calculated apparent resistivity and phase. The major features in the observations were explained by the model, although, the observed phase data seem noisy at $-20 \mathrm{~km}$ to $+5 \mathrm{~km}$ in the period range between $1 \mathrm{~s}$ to $1,000 \mathrm{~s}$.

The heterogeneity in the mid crust at $10-20 \mathrm{~km}$ depth (Fig. 7) comes from the data in the $1-100 \mathrm{~s}$ periods. We have conductors and resistors where we have high phase $\left(>45^{\circ}\right)$, and low phase $\left(<45^{\circ}\right)$ respectively. The distributions of the induction vectors at the period of $10 \mathrm{~s}$ (Fig. 4(b)) also show consistent features. The induction vectors point to the areas of high phase in the periods of $1-100 \mathrm{~s}$.

\section{Discussion and Conclusion}

To the east of the ISTL, the Minochi belt is a conductive layer, $6 \mathrm{~km}$ thick, corresponding to the actively folded sedimentary and volcanic layers. Below $10 \mathrm{~km}$ depth, there is a conductor, whose top deepens towards the east. The deep conductor disappears beneath the Takai-Utsukusigahara belt. There is a possibility that such a high conductivity anomaly represents a zone of enhanced porosity due to strong shear in the localized deformation area (Ogawa et al., 2001; Wannamaker et al., 2002).

In Fig. 4, also shows earthquake hypocenters determined by the Japan Meteorological Agency (Yuzo Ishikawa, personal communication). These hypocenters are generally located in resistive regions near the boundaries. Very few hypocenters are located within conductors. These may imply that the earthquakes are triggered by migration of fluid to less permeable (more resistive) crust (Ague et al., 1998; Ogawa et al., 2001; Mitsuhata et al., 2001).

Under the Japan Alps, the lower crust and the upper mantle are relatively conductive. We calculated the variance of the resistivity of each blocks and found that the tops of the deep conductors at $10-20 \mathrm{~km}$ are well resolved but the deeper continuations to the upper mantle are not.

We can compare our resistivity model with the seismic tomography result to a depth of $15 \mathrm{~km}$ around the Japan Alps. Seismic tomography (Matsubara et al., 2000) revealed two zones of low P-wave velocity. One is located at $4 \mathrm{~km}$ depth and the other at $15 \mathrm{~km}$ depth (bottom of the upper crust) under Mt. Tateyama, central part of the Japan Alps. Our MT result has the corresponding low resistivity anomalies at both levels. From $V p / V s$ analyses, Matsubara et al. (2000) inferred that the low velocity anomaly at $15 \mathrm{~km}$ depth can be explained by rocks with $5 \%$ partial melt having tubelike pore geometry. We can estimate the porosity from the resistivity model using Archie's law. If we assume melt resistivity as 0.01 to $0.1 \Omega \mathrm{m}$ (Haak and Hutton, 1986), and the cementation factor as 1.3 to 2 , the corresponding porosity to the resistivity of $30 \Omega \mathrm{m}$ at $15 \mathrm{~km}$ depth will be 0.2 to $6 \%$. If the melt is $0.1 \Omega \mathrm{m}$ and the cementation factor is $2, \mathrm{MT}$ and seismic result can give consistent porosity estimates.

Although ISTL is located the edge of the tomography study area, and the tomography shows high $V p$ velocity towards the ISTL (Fig. 7(b)). On the other hand, MT result showed that the mid crust east of ISTL is conductive. This 
may seem inconsistent with the seismic tomography. However, this might be caused by the different sensitivity to the structure (Yoshihisa Iio, personal communication). If there is a fluid distribution in a film-like geometry, there is a possibility that MT can resolve the anomaly, but seismic methods cannot. If we assume a crustal fluid resistivity as $0.04 \Omega \mathrm{m}$ as a typical crustal fluid resistivity (Nisbett, 1993), we can infer the porosity from the Archie's law. Corresponding to the possible cementation factors ( $m=1.3$ to 2 ), the porosity estimates for $30 \Omega \mathrm{m}$ conductive anomaly will be $0.6-3.7 \%$. If we assume a film-like geometry (i.e., smaller $\mathrm{m}$ ), the porosity less than $1 \%$ will be preferred.

From the geological investigations, ISTL requires doubleramp geometry as shown by the dotted lines in Fig. 7 (Hiroshi Sato, personal communication). This is required to explain the development of the geological structure to the east of ISTL, especially the uplifting of the basement in the Takai-Utsukusigahara belt. If we assume this geometry, the deep extension of the fault will be within the conductor under the Komoro Collapse basin as shown in Fig. 7. This conductor may accommodate the deep slip of the fault.

This magnetotelluric dataset still demand further multidimensional modeling of the resistivity structure. The planned coincident seismic reflection profiling in 2002 will reveal the geometry of the fault in detail and advance the geophysical and geological implications of the resistivity structure, in particular the deep conductor under the folding area and the deep extension of the fault in the lower crust.

Acknowledgments. This study is a part of the program "Comprehensive joint research on the modeling of slip process of earthquake source fault and plastic flow below the seismogenic region" which is funded by Japanese Ministry of Education, Culture, Sports, Science and Technology. We thank discussions with Yoshihisa Iio, Yoji Kobayashi, Hisao Ito, Hiroshi Sato, Yuzo Ishikawa, Takeshi Sagiya, Koichiro Fujimoto, and Makoto Uyeshima. The magnetotelluric data acquisition was done by Sumiko Consultants Co. Ltd. The comments from Martyn Unsworth and an anonymous referee improved the manuscript very much.

\section{References}

Ague, J., J. Park, and D. M. Rye, Regional metamorphic dehydration and seismic hazard, Geophys. Res. Lett., 25, 4221-4224, 1998.

Fujimoto, K., T. Ohtani, N. Shigematsu, Y. Miyashita, T. Tomita, H. Tanaka, K. Omura, and Y. Kobayashi, Water-rock interaction observed in the brittle-plastic transition zone, Earth Planets Space, 54, this issue, 1127 1132, 2002.

Gamble, T. D., W. M. Goubou, and J. Clarke, magnetotellurics with a remote reference, Geophysics, 81, 69-89, 1979.

Groom, R. W. and R. C. Bailey, Decomposition of magnetotelluric impedance tensors in the presence of local three-dimensional galvanic distortions, J. Geophys. Res., 94, 1913-1925, 1989.

Haak, V. and R. Hutton, Electrical resistivity in continental lower crust, in The Nature of the Lower Continental Crust, edited by J. B. Dawson, D. A. Carswell, J. Hall, and K. H. Wedepohl, Geological Society Special Publication, no. 24, 35-49, 1986.

Harayama, S., Youngest exposed granitoid pluton on Earth: Cooling and rapid uplift of the Pliocene-Quaternary Takidani Granodiorite in the Japan Alps, central Japan, Geology, 20(7), 657-660, 1992.

Honkura, Y., A. M. Işikara, N. Oshiman, A. Ito, B. Üçer, S. Bariş, M. K. Tunçer, M. Matsushima, R. Pektaş, C. Çelik, S. B. Tank, F. Takahashi,
M. Nakanishi, R. Yoshimura, Y. Ikeda, and T. Komut, Preliminary results of multidisciplinary observations before, during and after the Kocaeli (Izmit) earthquake in the western part of the North Anatolian Fault Zone, Earth Planets Space, 52, 293-298, 2000.

Iio, Y. and Y. Kobayashi, A physical understanding of large intraplate earthquakes, Earth Planets Space, 54, this issue, 1001-1004, 2002.

Ikeda, Y., The fact of topographical observation about the form of the Hida mountains, Earth Monthly, 18, 62-76, 1996 (in Japanese).

Jones, A. G., Electrical conductivity of the lower continental crust, in Continental Lower Crust, edited by D. M. Fountain, R. J. Arculus, and R. W. Kay, Elsevier, New York, 1992.

Kobayashi, Y., Initiation of plate subduction, Earth Monthly, 3, 510-518, 1983 (in Japanese).

Lemonnier, C., G. Marquis, F. Perrier, J.-P. Avouac, G. Chitrakar, B. Kafle, S. Sapkota, U. Gautam, G. Tiwari, and M. Bano, Electrical structure of the Himalaya of Central Nepal: High conductivity around the mid-crustal ramp along the MHT, Geophys. Res. Lett., 26, 3261-3264, 1999.

Matsubara, M., N. Hirata, S. Sakai, and I. Kawasaki, A low velocity zone beneath the Hida Mountains derived from dense array observation and tomographic method, Earth Planets Space, 52, 143-154, 2000.

Mitsuhata, Y., Y. Ogawa, M. Mishina, T. Kono, T. Yokokura, and T. Uchida, Electromagnetic heterogeneity of the seismogenic region of 1962 M6.5 Northern Miyagi Earthquake, northeastern Japan, Geophys. Res. Lett., 28, 4371-4374, 2001.

Nakamura, K., Possible nascent trench along the eastern Japan Sea as the convergent boundary between Eurasian and North American plates, Bull. Earthq. Res. Inst. Univ. Tokyo, 58, 711-722, 1983 (in Japanese).

Nesbitt, B. E., Electrical resistivity of crustal fluids, J. Geophys. Res., 98, 4301-4310, 1993.

Ogawa, Y., On two-dimensional modeling of magnetotelluric field data, Surveys in Geophysics, 23(2-3), 251-273, 2002.

Ogawa, Y. and T. Uchida, A two-dimensional magnetotelluric inversion assuming Gaussian static shift, Geophys. J. Int., 126, 69-76, 1996.

Ogawa, Y., M. Mishina, T. Goto, H. Satoh, N. Oshiman, T. Kasaya, Y. Takahashi, T. Nisitani, S. Sakanaka, M. Uyeshima, Y. Takahashi, Y. Honkura, and M. Matsushima, Magnetotelluric imaging of fluids in intraplate earthquakes zones, NE Japan back arc, Geophys. Res. Lett., 28, 3741-3744, 2001.

Okumura, K., K. Shimokawa, H. Yamazaki, and E. Tsukuda, Recent surface faulting along the middle section of Itoigawa-Shizuoka tectonic linetrenching survey of the Gofukuji fault near Matsumoto, central Japan, Zishin, 46, 425-438, 1994 (in Japanese).

Sagiya, T., T. Nishimura, Y. Iio, and T. Tada, Crustal deformation around the northern and central Itoigawa-Shizuoka Tectonic Line, Earth Planets Space, 54, this issue, 1059-1063, 2002.

Sato, H. and Y. Ikeda, Crustal structure of NE Japan and extension tectonics, Earth Monthly, special volume, 27, 135-141, 1999 (in Japanese).

Sato, H., T. Imaizumi, T. Yoshida, H. Ito, and A. Hasegawa, Tectonic evolution and deep to shallow geometry of Nagamachi-Rifu Active Fault System, NE Japan, Earth Planets Space, 54, this issue, 1039-1043, 2002

Umino, N., K. Nida, A. Hasegawa, and H. Sato, Microearthquake activity in the focal areas of large earthquakes that occurred in the last $\sim 100$ years in northeastern Japan, 2000 Japan Earth and Planetary Science Joint Meeting, Se-018, 2000.

Unsworth, M., G. Egbert, and J. Booker, High-resolution electromagnetic imaging of the San Andreas fault in Central California, J. Geophys. Res. 104, 1131-1150, 1999.

Wannamaker, P. E., S. H. Ward, and G. W. Hohmann, Magnetotelluric responses of three-dimensional bodies in layered earth, Geophysics, 49, 1517-1533, 1984

Wannamaker, P. E., G. R. Jiracek, J. A. Stodt, T. G. Caldwell, V. M. Gonzalez, J. D. McKnight, and A. D. Porter, Fluid generation and pathways beneath an active compressional orogen, the New Zealand Southern Alps, inferred from magnetotelluric data, J. Geophys. Res., 10.1029/2001JB000186, 2002

Y. Ogawa (e-mail: oga@ksvo.titech.ac.jp), S. Takakura, and Y. Honkura 